\title{
Ionospheric response to a geomagnetic storm during November 8-10, 2004
}

\author{
K. G. Simi ${ }^{1}$, G. Manju², M. K. Madhav Haridas², S. R. Prabhakaran Nayar ${ }^{1}$, Tarun Kumar Pant ${ }^{2}$, and S. Alex ${ }^{3}$ \\ ${ }^{1}$ Department of Physics, University of Kerala, India \\ ${ }^{2}$ Space Physics Laboratory (SPL, VSSC) Trivandrum, India \\ ${ }^{3}$ Indian Institute of Geomagnetism (IIG Mumbai), India
}

(Received December 20, 2011; Revised September 10, 2012; Accepted September 14, 2012; Online published May 7, 2013)

\begin{abstract}
This paper investigates the response of the equatorial, and near equatorial, ionosphere to geomagnetic disturbances during the period November $8-10,2004$. Ionosonde data from Trivandrum $\left(8.5^{\circ} \mathrm{N} 77^{\circ} \mathrm{E}\right.$ and dip $\left.0.5^{\circ} \mathrm{N}\right)$ and SHAR $\left(13.5^{\circ} \mathrm{N}, 80.2^{\circ} \mathrm{E}\right.$, dip $\left.\sim 5.5^{\circ} \mathrm{N}\right)$, magnetic field data from Tirunelveli $\left(8.7^{\circ} \mathrm{N}, 76.9^{\circ} \mathrm{E}\right.$, dip latitude $\left.0.5^{\circ} \mathrm{S}\right)$ and Alibag $\left(18.64^{\circ} \mathrm{N}, 72.87^{\circ} \mathrm{E}\right)$, and GUVI O/ $\mathrm{N}_{2}$ data in the Indian longitude sector, are used for the study. The behavior of interplanetary parameters is also examined in conjunction with the ionospheric data. On 8 November, the EIA around noontime is not fully inhibited even though the electrojet strength an indicates inhibition of EIA due to a disturbance dynamo electric field effect. It is the enhanced $\mathrm{O} / \mathrm{N}_{2}$ over TRV and SHAR, with a larger increase over SHAR, which results in a larger (than expected) value of the EIA proxy parameter. On 9 November, the comparable values of $f_{\mathrm{o}} F_{2}$ at TRV and SHAR around noon time is due to the combined effect of a weakened anomaly in the presence disturbance dynamo electric field effects leading to the EIA crest being near SHAR, and increased $\mathrm{O} / \mathrm{N}_{2}$ values at TRV and SHAR with a larger increase at TRV. On 10 November, the very strong values of the EIA proxy-SHAR parameter is attributed to the combined effects of prompt penetration electric field related modulations of EIA, and significant $\mathrm{O} / \mathrm{N}_{2}$ changes at the equatorial, and near equatorial, latitude. Thus, the study reveals the important role of storm-induced $\mathrm{O} / \mathrm{N}_{2}$ changes, along with prompt penetration electric fields and disturbance dynamo electric fields in modulating the ionization distribution in the equatorial ionization anomaly (EIA) region during this period.
\end{abstract}

Key words: Geomagnetic storm, Equatorial Ionization Anomaly (EIA), O/ $\mathrm{N}_{2}$ ratio, Equatorial Electrojet (EEJ).

\section{Introduction}

The ionospheric response to changes in solar wind conditions has been the subject of intense study for many years (Blanc and Richmond, 1980; Fuller-Rowell et al., 1997; Prolss, 1997; Buonsanto, 1999; Richmond and Lu, 2000). The interactions of the solar wind, magnetosphere, thermosphere, and ionosphere, cause dynamical changes over different spatial and temporal scales. According to Gonzalez et al. (1994), a magnetic storm occurs when a longlasting interplanetary convection electric field leads to an intensified ring current sufficiently strong enough to exceed some key threshold of the quantifying storm time Dst index. The disturbed thermospheric circulation changes, and the thermospheric meridional wind moves the plasma along magnetic field lines, changing the neutral composition and, consequently, the recombination rates of ionized species (Fuller-Rowell et al., 2002; Fedrizzi, 2003). The penetration of the interplanetary electric field (IEF) to the equatorial ionosphere results from the interactions of the solar wind, magnetosphere, and ionosphere (Maruyama et al., 2005). During magnetically-disturbed conditions, the low-latitude electric fields and currents change substantially from their quiet time pattern (Fejer, 2002). When the in-

Copyright (C) The Society of Geomagnetism and Earth, Planetary and Space Sciences (SGEPSS); The Seismological Society of Japan; The Volcanological Society of Japan; The Geodetic Society of Japan; The Japanese Society for Planetary Sciences; TERRAPUB.

doi:10.5047/eps.2012.09.005 terplanetary magnetic field (IMF) is southward at the magnetopause, the connection of flux lines occurs and the geomagnetic field lines become open, enabling the IEF to penetrate to the polar ionosphere. For an intense southward IMF, the inward plasma sheet convection occurs resulting in an enhancement of magnetospheric ring current and formation of a magnetic storm. The electron density of the $F_{2}$-region of the ionosphere is reflected in the values of the critical frequency $f_{\mathrm{o}} F_{2}$. During magnetic storms, the diurnal pattern of $f_{\mathrm{o}} F_{2}$ is totally a quiet day pattern, depending on the nature of the interplanetary plasma conditions. The dawndusk IEF is found to influence the ionosphere electron density distribution and the dynamics of the ionosphere, causing drifts and changes in ionospheric parameters, such as the ionospheric drift velocity, $f_{\mathrm{o}} F_{2}$ and $h^{\prime} F$ (Davis et al., 1997; Fejer, 2002; Biktash et al., 2005).

The disturbance dynamo fields are associated with an increased energy deposition into the high-latitude ionosphere during geomagnetically active periods (Blanc and Richmond, 1980). Their effect on the ionosphere may be felt over time periods of several hours to days after geomagnetic storms. Storm-time equatorward winds result in a buildup of storm-time westward winds which, in turn, results in the reversal of the zonal electric field, if only a zonally symmetric situation is concerned. This is not a realistic situation as ionospheric conductivity variations do prevail, especially in the latitude regions below 300. Hence, the dayside eastward current is interrupted at the terminator re- 
sulting in charge accumulation and a dawn-dusk potential difference. This, in turn, manifests as a westward electric field on the dayside, and an eastward electric field on the nightside (Blanc and Richmond, 1980; Zhao et al., 2005).

There are interesting cases of initial westward PPEF and the ionospheric responses to them. Batista et al. (2006) discussed such a case with an unusual early morning development of the equatorial anomaly in the Brazilian sector during the Halloween magnetic storm of October 2003. They also discussed the characteristic changes in the $\mathrm{F}$ layer peak height over the equator during this storm event and discussed that the $\mathrm{F}$ layer peak height over the equator first decreased under a strong prompt penetration westward electric field, which was followed by a significant height increase under an eastward electric field. Based on simulation results, they showed that the prompt penetration of magnetospheric electric fields of a westward polarity to the nightside equatorial region seems to be the most probable cause of the initial F layer height decreases. There are some cases where undershielding and overshielding PPEF successively affect the daytime equatorial ionosphere during geomagnetic storm events. Recently, Simi et al. (2012) described a case study of such event. They studied the ionospheric response of a geomagnetic storm (November 24, 2001) over the equatorial latitude of Trivandrum and discussed the highest EEJ strength during that time, which was extreme for the entire solar cycle for the month of November. This unusually large EEJ showed an equally strong polarity reversal along with a weakening of the sporadic Elayer over the equator due to an overshielding condition. The uniqueness of the event studied by them is that the main phase continued, even after the overshielding event, and it triggered the recovery of a substorm. They also studied the latitudinal variation of the F-region electron density, and Sporadic E.

The chemical effects of neutral winds also play a very important role in producing stormtime changes in the ionosphere. During a geomagnetic storm, intense Joule and particle heating causes a strong upwelling of the atmosphere around the auroral oval. The strong upwelling of the atmosphere transports oxygen-depleted, or nitrogen-rich, air up from much lower in the thermosphere into the $\mathrm{F}$ region (Mayr and Volland, 1972; Mayr et al., 1978; Prolss, 1980). Neutral winds then redistribute this nitrogenrich/oxygen-depleted air over much of the high-latitude region and part of the mid-latitude region. The nitrogenrich/oxygen-depleted air causes a reduction in the ionospheric electron density, and oxygen-rich/nitrogen-depleted air causes an increase in the ionospheric electron density. The transport is strongest during post-midnight hours owing to wind surges arising from ion convection and the associated momentum transfer to neutrals. It is known that, during daytime, the bottom side of the ionosphere (130-200 $\mathrm{km}$ ) is "photochemically" governed, where photodissociation of molecular oxygen in the Schumann-Runge continuum $(135-175 \mathrm{~nm})$ leads to the generation of atomic oxygen, which, in turn, leads to the formation of ionization. At the same time, the ionization loss processes are mainly controlled by molecular nitrogen through chemistry. As a result, the ratio $\left(\mathrm{O} / \mathrm{N}_{2}\right)$ at any time is taken as a measure of the net ionization in the lower F region (Forbes, 2007).

The mechanical effects of neutral winds during geomagnetic disturbances form another important aspect which has a significant impact on the ionosphere. Balan et al. (2010, 2012) have discussed this aspect in detail. The equatorward winds associated with geomagnetic disturbances have mechanical effects which are proportional to $U \cos I$ and $U$ $\cos I \sin I$, where $I$ is the dip angle. Both these effects result in electron density enhancements at all heights at the equator, and the effect varies at other latitudes proportionately with the dip angle.

The storm of November 2004, which is the subject matter of the present study, has been discussed by several workers in the past. Balan et al. (2008a) investigated the magnetosphere-ionosphere coupling through a prompt penetration electric field (PPEF) in response to a CME during 7-12 November, 2004. They analyzed this event using cluster and ground-based (ESR, EISCAT and Jicamarca radars and magnetometer) observations and found that this event is characterized by the strongest PPEF ever recorded. This was observed on November 9, 2004. This PPEF was generated in the magnetosphere by the $v \times B$ effect, which was mapped to the high-latitude ionosphere along the geomagnetic field lines and promptly penetrated to low latitudes. Dabas et al. (2006) also reexamined the response of the ionosphere to this particular storm. They looked into the $f_{\mathrm{o}} F_{2}$ and $h^{\prime} F$ variations observed at a low-latitude station at Delhi. They observed a sharp enhancement in $f_{\mathrm{o}} F_{2}$ values during the forenoon hours on November 8, 2004, and a sharp rise in $h^{\prime} F$ around the period of Dst maximum negative excursion during nighttime on November 9-10, 2004. Fejer et al. (2007) studied the electric fields over equatorial ionosphere during the November 7-9, 2004, geomagnetic storm, using radar measurements from the Jicamarca Radio Observatory, magnetometer observations from the Pacific sector and ionosonde data from Brazil. They showed very large eastward and westward daytime electrojet current perturbations with lifetimes of about an hour (indicative of undershielding and overshielding prompt penetration electric fields) in the Pacific equatorial region during November 7, which was the main phase of the storm. Their results highlight that the relationships between prompt penetration, solar wind electric fields, and polar cap potentials, are far more complex than implied by simple proportionality factors.

The dayside ionospheric response to geomagnetic storms including the storm of November 2004 has been analyzed by Astafyeva (2009) using simultaneous Total Electron Content (TEC) measurements by the CHAMP, SACC, TOPEX/Jason-1 satellites. Since the satellites passed over different longitudinal sectors, and measured TEC in a different range of altitudes, they could obtain information about the altitudinal, and longitudinal, ionosphere redistribution during these storms. In their analysis they observed severe enhancements of the equatorial and midlatitude TEC above $\sim 430 \mathrm{~km}$, with a concurrent movement of the equatorial anomaly crests over a distance of $10-15^{\circ}$ on November 08,2004 . As is known, during the main phase of geomagnetic storms, when the interplanetary magnetic field (IMF) turns southward and intensifies, the 

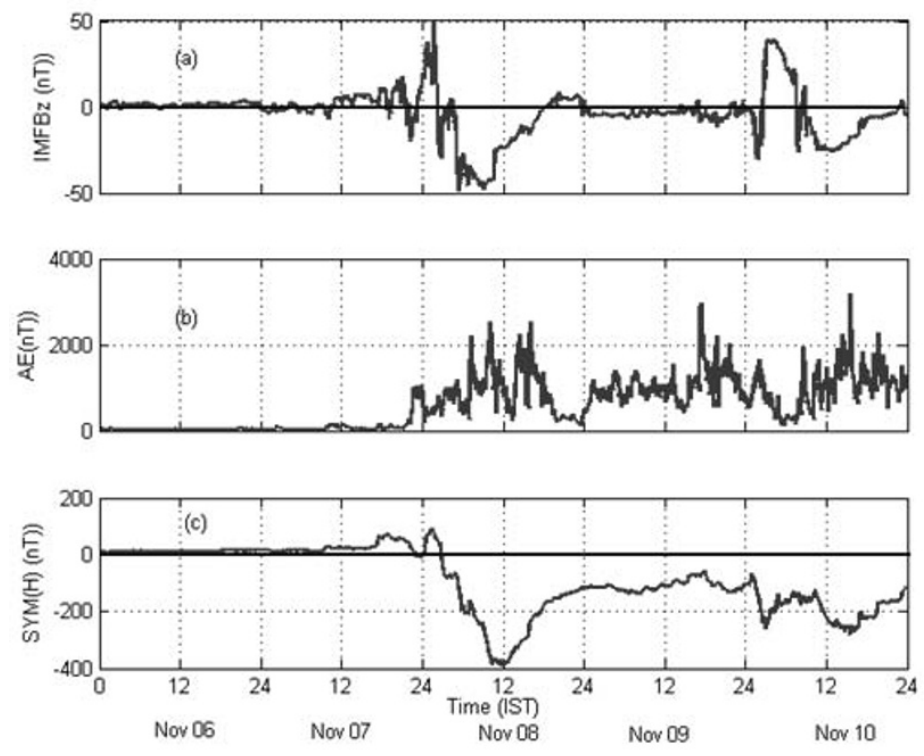

Fig. 1. Variations in (a) IMF $B_{z}$, (b) the AE index, and (c) SYM (H) during November 6-10, 2004.

interplanetary electric field can penetrate to the low-latitude ionosphere for many hours. The reconnection between the southward IMF and the Earth's magnetic field leads to a strong dawn-to-dusk electric field and enhances the equatorial fountain effect. Solar photoionization replaces the uplifted plasma at lower altitudes. An overall increase in the ionosphere total electron content (TEC) in response to this has been analyzed by several workers (e.g., Vlasov et al., 2003; Tsurutani et al., 2004; Mannucci et al., 2005; Astafyeva et al., 2007; Basu et al., 2007). In the present paper, we discuss the storm-induced modulations of EIA over Indian longitudes during the period 8-10 November 2004.

\section{Data and Method of Analysis}

For a detailed study of interplanetary magnetospheric activity impact on the equatorial $F$ region, the ionospheric features are analyzed by using the data obtained from ionosondes at Trivandrum $\left(8.5^{\circ} \mathrm{N} 77^{\circ} \mathrm{E}\right.$ and $\left.\operatorname{dip} 0.5^{\circ} \mathrm{N}\right)$ and SHAR $\left(13.5^{\circ} \mathrm{N}, 80.2^{\circ} \mathrm{E}\right)$. The incident solar wind and associated magnetic field information was derived from the fiveminute resolution data of the Advanced Composition Explorer (ACE) satellite which was at a distance of $240 R_{E}$ from the Earth in the sunward direction. The data from the satellite was taken from the Coordinated Data Analysis (CDA) web.

The one-minute resolution magnetometer (PPM) data at Tirunelveli $\left(8.7^{\circ} \mathrm{N}, 76.9^{\circ} \mathrm{E}\right.$, dip latitude $\left.0.5^{\circ} \mathrm{S}\right)$ and Alibag $\left(18.64^{\circ} \mathrm{N}, 72.87^{\circ} \mathrm{E}\right)$, operated by the Indian Institute of $\mathrm{Ge}-$ omagnetism (IIG), is used to study the electrojet strength on the days of observation.

The neutral composition change can also affect the electron density distribution. Therefore, the contribution of the neutral composition changes to the columnar content is examined in terms of the changes produced in the daytime $\mathrm{O} / \mathrm{N}_{2}$ column density obtained from the GUVI instrument onboard the TIMED satellite. The TIMED satellite is in a $630 \mathrm{~km}, 97.8$-minutes-period circular orbit with an inclination of $74^{\circ}$. The satellite covers the same longitude at nearly the same local time on consecutive days, thus making day-to-day comparisons in the variations of the $\mathrm{O} / \mathrm{N}_{2}$ ratio feasible.

The GUVI column $\mathrm{O} / \mathrm{N}_{2}$ ratio is estimated from the $\mathrm{O}$ (135.6 $\mathrm{nm}$ ) and $\mathrm{N}_{2}$ (LBHS) airglow emissions, between about 140 and $250 \mathrm{~km}$ (Christensen et al., 2003; Paxton et al., 2004; Strickland et al., 2004), and is estimated with $\sim 1.75^{\circ} \times 1.75^{\circ}$ spatial resolution. With a lookup table generated by the model runs, Strickland et al. (2004) derived the $\mathrm{O} / \mathrm{N}_{2}$ ratio from the GUVI dayglow measurements. They showed that the estimated error in $\mathrm{O} / \mathrm{N}_{2}$ is $\sim 5 \%$ for low $\mathrm{O} / \mathrm{N}_{2}$ values and at lower latitudes (Strickland et al., 2004).

In our study, we have taken the averaged $\mathrm{O} / \mathrm{N}_{2}$ in the region from $6.5^{\circ} \mathrm{N}-10.5^{\circ} \mathrm{N}$ and $72^{\circ} \mathrm{E}-82^{\circ} \mathrm{E}$ as the representative value for the equatorial station, TRV. For SHAR, the $\mathrm{O} / \mathrm{N}_{2}$ value is obtained by averaging the values over the region $11.5^{\circ} \mathrm{N}-15.5^{\circ} \mathrm{N}$ and $75^{\circ} \mathrm{E}-85^{\circ} \mathrm{E}$.

\section{Results \\ 3.1 Interplanetary measurements}

From solar wind data available from the ACE satellite, coronal mass ejection effects were evident during 7-10 November as the solar wind velocity increased from 420 to $660 \mathrm{~km} / \mathrm{s}$, particle densities increased to $27 \mathrm{~cm}^{-3}$, and $B_{z}$ became strongly southward. As a result, during November $7-10$, two geomagnetic storms occurred. Figure 1 shows the time variations in IST (Indian standard time $=\mathrm{UT}+5.5$ hours) of the geomagnetic activity indices during 06-10 November, 2004: (a) IMF $B_{z}$, (b) the AE index (a measure of the auroral electrojet), and (c) the SYM-H index (a measure of the ring current (c) respectively.

As can be seen from Fig. 1(a), on November 8, IMF $B_{z}$ turned southward around 0215 IST and showed a strong negative component of $-48 \mathrm{nT}$ at 0542 IST. This $B_{z}$ southward turning (Skoug et al., 2004), combined with solar wind velocities in the range $420-600 \mathrm{~km} / \mathrm{s}$, caused a strong geomagnetic storm as the SYM-H index (Fig. 1(c)) reached 


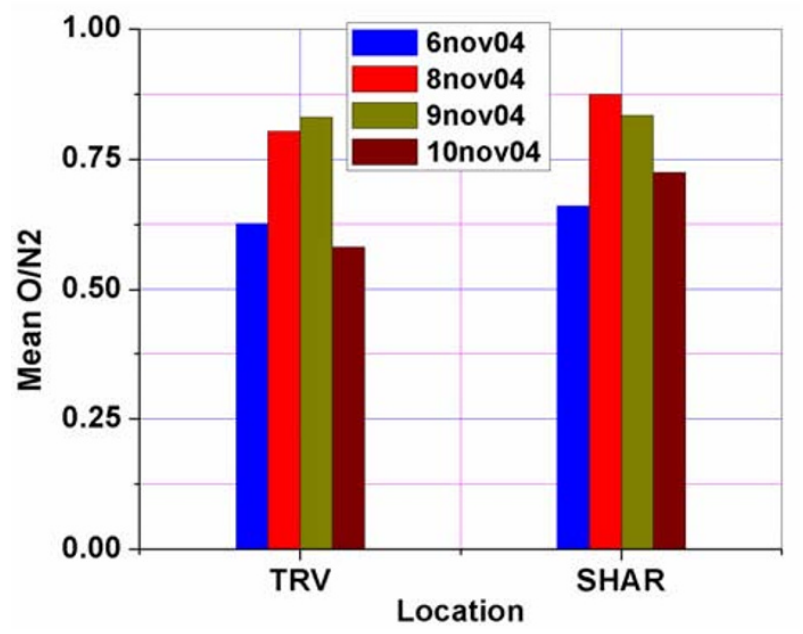

Fig. 2. GUVI O/N 2 values for the control day and 8-10 November, 2004.
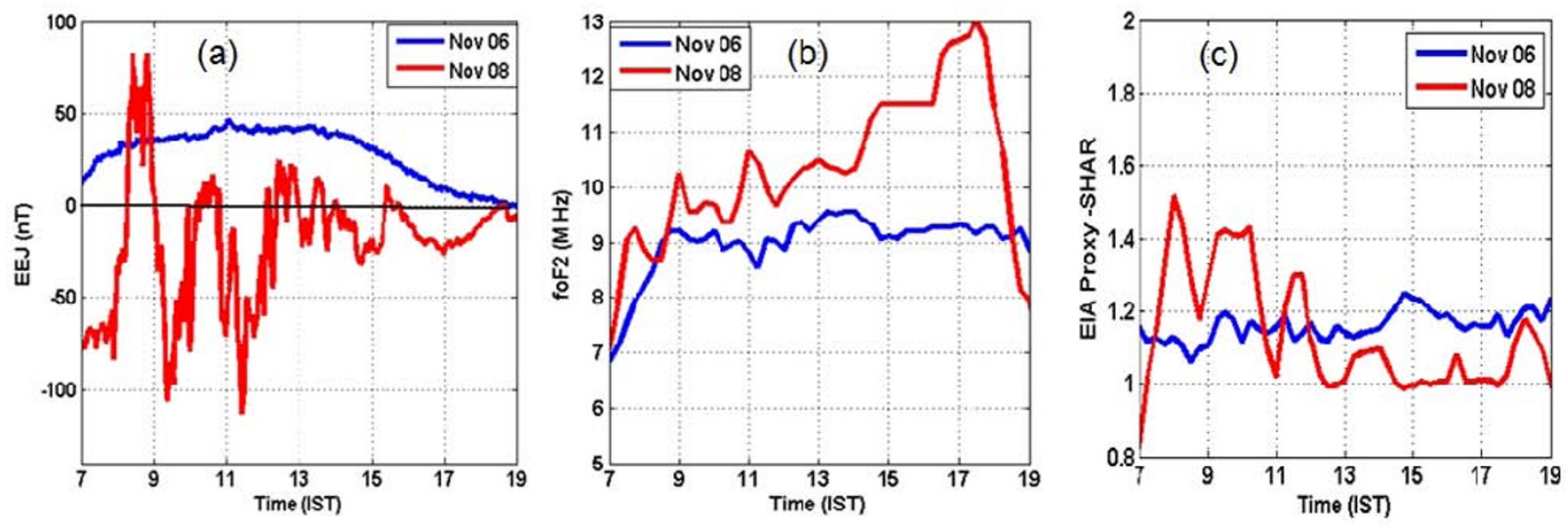

Fig. 3. Temporal variations of (a) EEJ, (b) $f_{\mathrm{o}} F_{2}$, and (c) EIA proxy-SHAR on 8 November 2004 and the control day.

a minimum value of $-363 \mathrm{nT}$ at around 1000 IST. This period is marked as the main phase of the storm. This is followed by a recovery phase, as is evident from the SYM (H) index and IMF $B_{z}$.The AE index (Fig. 1(b)) also exhibits a peak of $2189 \mathrm{nT}$ around this time.

3.2 Response of $\mathrm{O} / \mathrm{N}_{2}$ at TRV and SHAR for the storm period viz-a-viz the control day pattern

Figure 2 depicts the $\mathrm{O} / \mathrm{N}_{2}$ values for 8,9 and 10 November, 2004, along with the control day pattern for 6 November, 2004. For the control day, $\mathrm{O} / \mathrm{N}_{2}$ values of 0.62 and 0.66 , respectively, are observed at TRV and SHAR. On 8 November, the values are 0.8 and 0.87 , respectively, at TRV and SHAR. Thus, there is an increase of $\sim 1.29$ times and 1.32 times, respectively, at TRV and SHAR in comparison with the control day. Similarly on 9 November, the $\mathrm{O} / \mathrm{N}_{2}$ values are 0.83 (TRV) and 0.834 (SHAR), respectively, giving rise to an increase of $\sim 1.34$ times (TRV) and 1.26 times (SHAR). For 10 November, the $\mathrm{O} / \mathrm{N}_{2}$ values are 0.58 and 0.73 , respectively, at TRV and SHAR. Thus, there is a decrease of $\sim 0.94$ times at TRV and an increase of 1.11 times at SHAR. The above discussion clearly reveals that significant changes in $\mathrm{O} / \mathrm{N}_{2}$ are taking place during the disturbed days of 8,9 and 10 November, 2004, in relation to the con- trol day. The implications of these changes on the electron densities at the two stations are discussed in the following sections.

\subsection{Mechanical effect of neutral winds}

The mechanical effects of neutral winds, as mentioned earlier, are proportional to $U \cos I$ and $U \cos I \sin I$, respectively. The term $U \cos I$ results in a reduced diffusion of plasma along the field lines leading to plasma accumulation and convergence over the equator when winds from the two hemispheres reach the equator (Balan et al., 2010). The other term results in the rise of the $\mathrm{F}$ region peak leading to an increase in electron density. In the present case, the effects of both the above terms at TRV and SHAR would be nearly the same (as the cosine and sine of the dip angle vary only in the third decimal) and there would consequently be a nearly identical increase in ionization at both the stations.

\subsection{Response of Equatorial Ionization Anomaly (EIA)} during November 8, 2004

Examination of the IMF variation of November 8 (Fig. 1(a)) shows that IMF has a prolonged and strong southward trend. In response to this, the equatorial electrojet (EEJ) (Fig. 3(a)) also shows a large enhancement (due to prompt penetration electric field modulation) which is the 
largest of all the days considered, indicating the presence of a strong eastward electric field between $0800 \mathrm{hr}$ and 0900 hr. During post-midnight of November 7 (during the main phase of the storm) a large enhancement in the AE index occurs. This indicates a large energy and momentum deposition in the magnetosphere, which produces changes in the global circulation and consequent disturbance dynamo effects. As a result of the combined action of the disturbance dynamo and prompt penetration electric fields, a negative, or weak, EEJ is observed during the rest of the day after 0900 hr (Fig. 3(a)).

During the morning of November 8, EEJ shows a positive excursion and, naturally, we expect development of EIA, but from the $f_{\mathrm{o}} F_{2}$ variation (Fig. 3(b)) at Trivandrum (the magnetic equatorial location), we can see that it is much higher compared to the control day of November 6 . $f_{\mathrm{o}} F_{2}(\mathrm{SHAR}) / f_{\mathrm{o}} F_{2}$ (TRV) is taken as a proxy parameter for the strength of the EIA. If the proxy parameter $f_{\mathrm{o}} F_{2}$ (SHAR) $/ f_{\mathrm{o}} F_{2}$ (TRV) (hereafter referred to as EIA ProxySHAR) is greater than 1 , it indicates the presence of an anomaly, and if it is less than 1 it indicates the inhibition of an anomaly. The examination of the EIA proxy-SHAR on November 8 (Fig. 3(c)) reveals that the ratio is very high compared to the control day in the morning. This means that an EIA development is present in the morning on 8 November in response to prompt penetration electric field effects, as indicated by the electrojet strength $(\sim 0900 \mathrm{hr})$ also. In the post-noon phase, we can see a significant weakening of the EIA with the EIA proxy-SHAR being close to 1. This is the time when the disturbance dynamo electric fields are more dominant over the magnetic equatorial regions. The electrojet strength (Fig. 3(a)) in the noon phase of November 8 is either reversed, or very low compared to the control day. Under such conditions, we expect the EIA proxy-SHAR to be mostly less than 1, representing an inhibited EIA, but the observed values (EIA proxy-SHAR) are either 1 , or slightly greater than 1 . This indicates that there is some other factor modulating the ionization distribution during the post-noon phase of November 8 in the equatorial and near equatorial regions. The $\mathrm{O} / \mathrm{N}_{2}$ values over the Indian longitudes are available around 13:30 IST and, hence, it is possible to verify the possible role of $\mathrm{O} / \mathrm{N}_{2}$ in modulating the ionization distribution in this region. The enhanced $\mathrm{O} / \mathrm{N}_{2}$ at TRV and SHAR on 8 November is already depicted in Fig. 2. Further, the $\mathrm{O} / \mathrm{N}_{2}$ enhancement is relatively larger at SHAR than at TRV in relation to the control day pattern. This increase in $\mathrm{O} / \mathrm{N}_{2}$ is probably the reason for the EIA proxy-SHAR remaining around 1, even when an anomaly is expected to be fully inhibited with the electrojet strength being reversed. Another factor that has contributed equally to the overall increase in ionization, at both TRV and SHAR, is the mechanical effect of winds which has been discussed in Subsection 3.2. Burns et al. (1995) have examined the changes in the $\mathrm{O} / \mathrm{N}_{2}$ ratio during geomagnetic storms using DE2 satellite data, as well as theoretical simulations. According to them, a generally vertical wind blows upward in the afternoon and evening in the thermosphere, and these winds, blowing through a constant pressure surface, became less upward (and more downward) at low- to middle-latitudes in the winter hemisphere during a geomagnetic storm and change greatly. During disturbed conditions, the decrease in the upward wind results in a decrease in the rate of thermal expansion and, hence, a decrease in the cooling rate. Less nitrogen-rich air is now transported upward (or more nitrogen-poor air is transported downward), and $\mathrm{N}$ densities decrease, but $\mathrm{O}$ densities do not decrease because the vertical gradient of $\mathrm{O}$ is relatively small and the effects of a decreased expansion (or an increased compression) counter the effects of the changed vertical transport. So the net effect is an increase in the $\mathrm{O} / \mathrm{N}_{2}$ ratio in the low-middle latitude in the winter hemisphere during geomagnetically active conditions in the day time. A similar mechanism seems to be in operation during the present storm also.

Dashora and Pandey (2007) have studied this storm event and have reported disturbance dynamo related modulations of the total electron content (TEC) on November 8 using GPS. They showed higher values of $f_{\mathrm{o}} F_{2}$ on November 8 at TRV, in agreement with our results, wherein they are attributing the increase to a disturbance dynamo related inhibition of EIA. Our result indicates that increased $f_{\mathrm{o}} F_{2}$ at TRV is manifested not only because of an inhibition of EIA, but it also has a significant contribution from an increased $\mathrm{O} / \mathrm{N}_{2}$ ratio and mechanical wind effects at TRV in relation to the control day.

\subsection{Response of Equatorial Ionization Anomaly dur- ing November 9, 2004}

Figure 4(a) shows the EEJ variation for November 9 and the control day of November 6 . In this figure, a clear EEJ development is seen between 0800 and 1100 IST on November 9. In the time after 1100 IST, we find that there is a decrease in EEJ up to 1200 IST, followed by a very weak, or inhibited, EEJ up to nearly 1500 IST. The $f_{\mathrm{o}} F_{2}$ at TRV (Fig. 4(b)) shows higher values throughout the day. But the EIA proxy-SHAR (Fig. 4(c)), with greater values than for the control day, indicates the presence of a strong EIA in the time period between 0800 IST and 1000 IST. Afterwards, EIA proxy-SHAR starts decreasing and reaches a value close to 1 by $\sim 1500$ IST. Although the EEJ is very weak in the post-1300 IST period, the EIA proxy-SHAR does not go much below 1 , as expected for this time when EEJ is mostly reversed.

In this context, $f_{\mathrm{o}} F_{2}$ at TRV and SHAR are examined. Figure 4(d) shows the $f_{\mathrm{o}} F_{2}$ at TRV and SHAR on 9 and 6 November in the post-noon sector around 1330 IST, corresponding to the $\mathrm{O} / \mathrm{N}_{2}$ data availability. From the figure, it is seen that $f_{\mathrm{o}} F_{2}$ is higher on 9 November compared with the control day, at both TRV and SHAR. This observation indicates that the EIA proxy-SHAR is greater than 1 as expected on the 6 , while, on the 9 , when the EIA is relatively weak, the EIA proxy-SHAR is only 1, or slightly above 1 . It seems that the EIA crest is present between TRV and SHAR due to a weakening of EIA around this time, while, on the control day, with a stronger EIA development, the crest is expected to manifest at still higher latitudes beyond SHAR. It is evident that the crest has not reached TRV because, in that case, the $f_{\mathrm{o}} F_{2}$ would have been a maximum there, and the proxy parameter would fall below 1. Thus, the EIA effect, and the mechanical and chemical effect of winds, act in such a way that the ionization distribution is identical at 

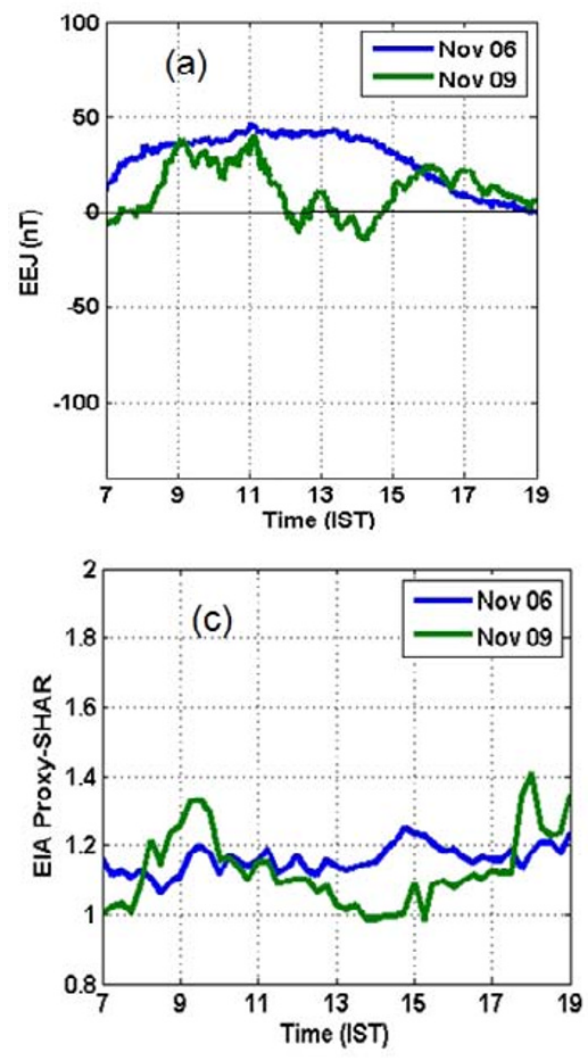
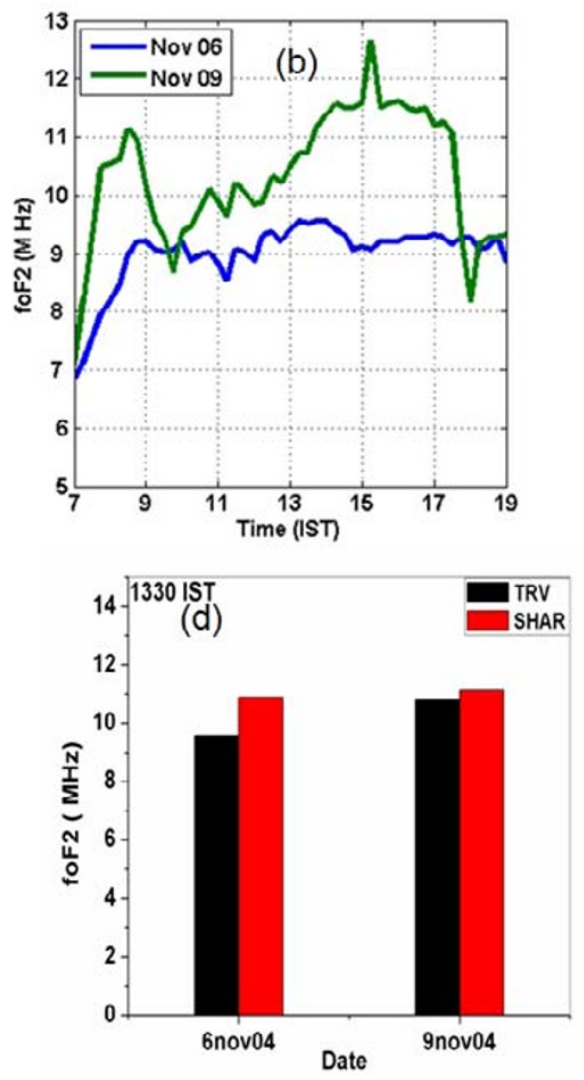

Fig. 4. Temporal variations of (a) EEJ, (b) $f_{\mathrm{o}} F_{2}$, (c) EIA proxy-SHAR, and (d) post-noon $f_{\mathrm{o}} F_{2}$ at TRV and SHAR, on 9 November, 2004 , and the control day.
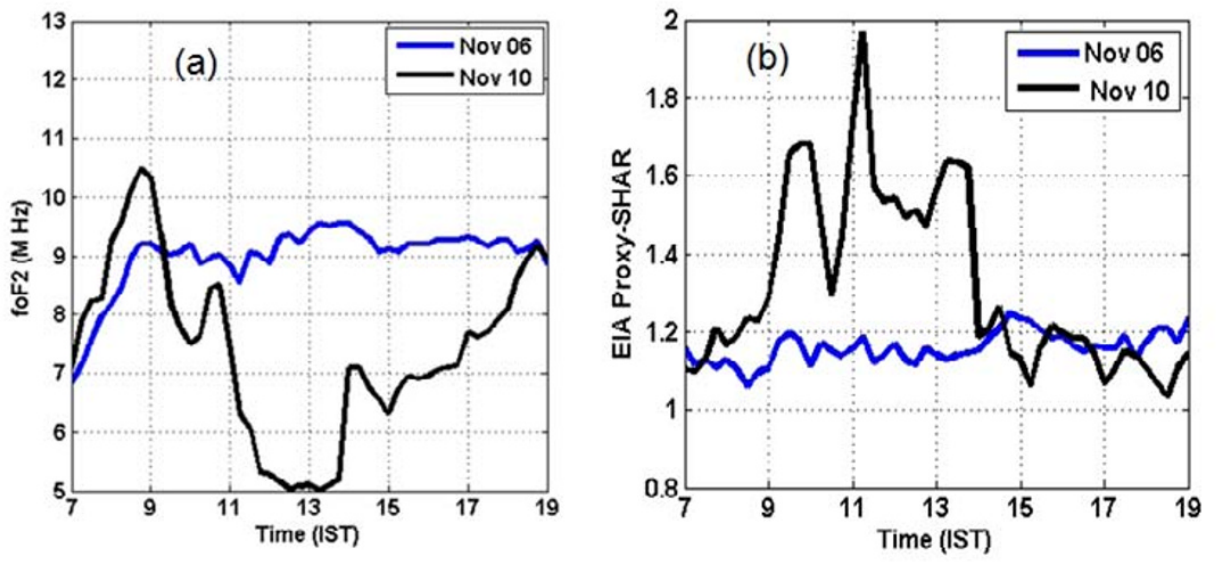

Fig. 5. Temporal variations of (a) $f_{\mathrm{o}} F_{2}$, and (b) EIA proxy-SHAR, on 10 November, 2004, and the control day.

TRV and SHAR.

It has been reported by Manju et al. (2008) that large spatial fluctuations exist in the plasmaspheric electron content (PEC) on November 9 at TRV, and near the equatorial station Bangalore, which is near SHAR. The present study reveals a significant ionospheric electron content variability also on this day.

3.6 Response of Equatorial Ionization Anomaly during November 10, 2004

An examination of the IMF variation for 10 November, 2004 (Fig. 1(a)) shows that between 0700 IST and
0900 IST there is a sequence of oscillations towards the southward and northward directions. The southward tuning of $B_{z}$ at $\sim 0900$ IST is a prolonged one, persisting up to evening. This indicates that probably prompt penetration electric fields are modulating the EEJ throughout the day. The EEJ strength was not available due to a problem with the data on this day. The $f_{\mathrm{o}} F_{2}$ values (Fig. 5(a)), are higher on November 10 than on November 6 between 0800 and 0900 IST. After that, $f_{\mathrm{o}} F_{2}$ shows a decrease compared with the control day up to around 1800 IST. The temporal variation of EIA proxy-SHAR has also been examined, 
which shows a strong development of EIA up to the period around 1500 IST (Fig. 5(b)) after which a reduction in EIA strength occurs. Again $\mathrm{O} / \mathrm{N}_{2}$ data is available for around 1330 IST, so that we are able to examine its possible role in the increased strength of the EIA during the time period up to 1500 IST.

As discussed previously, $\mathrm{O} / \mathrm{N}_{2}$ values show changes on November 10 (Fig. 2) as compared with the control day with higher values at SHAR and lower values at TRV. This also contributes significantly to the EIA strength. The observation of F3 layers are a feature during the day on 10 November. Balan et al. (2008b) have examined the occurrence of the F3 layer at equatorial stations in American, Indian and Australian longitudes during the super double geomagnetic storm of 7-11 November, 2004, using observations and modeling. From their studies, they have inferred that the sudden appearance of an unusually strong F3 layer, with large reductions in Nmax and TEC, can indicate a strong eastward electric field (PPEF). Our result is in agreement with their results as we also observe the signatures of enhanced vertical drift and fountain as a consequence of prompt penetration effects and disturbance-induced effects on $\mathrm{O} / \mathrm{N}_{2}$.

\section{Discussion}

Storm-time alterations to the equatorial zonal electric field, as already mentioned, fall into two broad groups, namely those due to a prompt penetration electric field and those due to a disturbance dynamo electric field (Blanc and Richmond, 1980) both of which are manifested at equatorial latitudes and are the result of a magnetosphere-ionosphere interaction (Basu et al., 2001; Sobral et al., 2001). The dawn-dusk Interplanetary Electric Field (IEF) is found to influence the ionosphere electron density distribution and the dynamics of the ionosphere, causing drifts and changes in ionospheric parameters such as the ionospheric drift velocity, $f_{\mathrm{o}} F_{2}$ and $h^{\prime} F$ (Davis et al., 1997; Fejer, 2002; Biktash et al., 2005). The strong upwelling of the atmosphere transports oxygen-depleted, or nitrogen-rich, air up from much lower in the thermosphere into the $\mathrm{F}$ region (Mayr and Volland, 1972; Mayr et al., 1978; Prolss, 1980). The nitrogen-rich/oxygen-depleted air causes a reduction in the ionospheric electron density and oxygen rich/nitrogendepleted air causes an increase in the ionospheric electron density (Zhang et al., 2004).

Several workers have investigated the storm event of November 8-10, 2004, which is discussed in this paper (Balan et al., 2008a; Dabas et al., 2006; Fejer et al., 2007; Dashora and Pandey, 2007; Astafyeva, 2009). In these papers, the effects of storm-time electric fields in modulating ionization distribution is stressed. In the present paper, we are showing that storm-induced changes in $\mathrm{O} / \mathrm{N}_{2}$ also play a significant role, in conjunction with the storm-time electric fields, in modulating the spatial distribution of ionization in the EIA at a given time. In fact, the time instances for which $\mathrm{O} / \mathrm{N}_{2}$ data are available over Indian longitudes amply demonstrate that the storm-time changes in $\mathrm{O} / \mathrm{N}_{2}$ are very significant and contribute substantially to the electron density at TRV and SHAR. It is therefore clear that one needs to incorporate the possible effects of $\mathrm{O} / \mathrm{N}_{2}$ changes, in ad- dition to those due to disturbance-related electric fields and the mechanical effect of neutral winds, to be able to explain accurately the ionization distribution.

\section{Conclusion}

In this paper, we have described the unusual equatorial, and near equatorial, ionospheric response to the geomagnetic disturbances of November 8-10, 2004. The interesting aspect is that the modulation of the electron density distribution in the EIA region is brought about by storminduced changes in $\mathrm{O} / \mathrm{N}_{2}$, and the mechanical effect of neutral winds, rather than purely by the expected disturbanceinduced changes in the fountain effect.

Acknowledgments. One of the authors, K. G. Simi is thankful to the Director of the Space Physics Laboratory, VSSC, Trivandrum, India, for providing the ionogram data. She also thanks Dr. Tarun Kumar Pant, Dy. Head, ITMP, SPL, for support and encouragement during the course of the work. The IMF $B_{z}, \mathrm{AE}$ index and SYM $(\mathrm{H})$ data were taken from the site http://cdaweb.gsfc.nasa.gov/cgi-bin/eval2.cgi. GUVI data is taken from their website. We thank the GUVI team for providing the data.

\section{References}

Astafyeva, E., Effects of strong IMF Bz southward events on the equatorial and mid-latitude ionosphere, Ann. Geophys., 27, 1175-1187, 2009.

Astafyeva, E. I., E. L. Afraimovich, and E. A. Kosogorov, Dynamics of total electron content distribution during strong geomagnetic storms, Adv. Space Res., 39, 1313-1317, doi:10.1016/j.asr.2007.03.006, 2007.

Balan, N., H. Alleyne, S. Walker, H. Reme, I. McCrea, and A. Aylward, Magnetosphere-ionosphere coupling during the CME events of 07-12 November 2004, J. Atmos. Sol.-Terr. Phys., 70, 2101-2111, 2008a.

Balan, N., S. V. Thampi, K. Lynn, Y. Otsuka, H. Alleyne, S. Watanabe, M. A. Abdu, and B. G. Fejer, F3 layer during penetration electric field, $J$. Geophys. Res., 113, A00A07, doi:10.1029/2008JA013206, 2008b.

Balan, N., K. Shiokawa, Y. Otsuka, T. Kikuchi, D. Vijaya Lekshmi, S. Kawamura, M. Yamamoto, and G. J. Bailey, A physical mechanism of positive ionospheric storms at low latitudes and midlatitudes, J. Geophys. Res., 115, A02304, doi:10.1029/2009JA014515, 2010.

Balan, N., J. Y. Liu, Y. Otsuka, S. Tulasi Ram, and H. Lühr, Ionospheric and thermospheric storms at equatorial latitudes observed by CHAMP, ROCSAT, and DMSP, J. Geophys. Res., 117, A01313, doi:10.1029/2011JA01690, 2012.

Basu, S., Su. Basu, K. M. Groves, H. C. Yeh, S. Y. Su, F. J. Rich, P. J. Sultan, and M. J. Keskinen, Ionospheric effects of major magnetic storms during the International Space Weather Period of September and October 1999: GPS observations, VHF/UHF scintillations, and in situ density structures at middle and equatorial latitudes, J. Geophys. Res., 106(A12), 30389-30413, doi:10.1029/2001JA001116, 2001.

Basu, S., Su. Basu, F. J. Rich, K. M. Groves, E. MacKenzie, C. Coker, Y. Sahai, P. R. Fagundes, and F. Becker-Guedes, Response of the equatorial ionosphere at dusk to penetration electric fields during intense magnetic storms, J. Geophys. Res., 12, A08308, doi:10.1029/2006JA012192, 2007.

Batista, I. S., M. A. Abdu, J. R. Souza, F. Bertoni, M. T. Matsuoka, P. O. Camargo, and G. J. Bailey, Unusual early morning development of the equatorial anomaly in the Brazilian sector during the Halloween magnetic storm, J. Geophys. Res., 111, A05307, doi:10.1029/2005JA011428, 2006.

Biktash, L. Z., L. Sizova, T. Maruyama, and K. Nozaki, The solar wind control of ionospheric dynamics during Magnetic storms, Geophys. Res. Abs., 7, 01612, 2005.

Blanc, M. and A. D. Richmond, The ionospheric disturbance dynamo, $J$. Geophys. Res., 85, 1669-1686, 1980.

Buonsanto, M. J., Ionospheric storms-A review, Space Sci. Rev., 88, 563$601,1999$.

Burns, A. G., T. L. Killeen, W. Deng, G. R. Carignan, and R. G. Roble, Geomagnetic storm effects in the low- to middle-latitude upper thermosphere, J. Geophys. Res., 100(A8), 14,673-14,691, 1995.

Christensen, A. B. et al., Initial observations with the Global Ultra-violet 
Imager (GUVI) in the NASA TIMED satellite mission, J. Geophys. Res., 108(A12), 1451, doi:10.1029/2003JA009918, 2003.

Dabas, S., R. M. Das, V. K. Vohra, and C. V. Devasia, Space weather impact on the equatorial and low latitude F-region ionosphere over India, Ann. Geophys., 24, 97-105, 2006.

Dashora, N. and R. Pandey, Variations in the total electron content near the crest of the equatorial ionization anomaly during the November 2004 geomagnetic storm, Earth Planets Space, 59, 127-131, 2007.

Davis, C. J., M. N. Wild, M. Lockwood, and Y. K.Tulunay, Ionospheric and geomagnetic responses to changes in IMF Bz: A superposed epoch study, Ann. Geophys., 15, 217-230, 1997.

Fedrizzi, Estudo do Efeito de Tempestades Magnéticas na Ionosfera Utilizando Dados do GPS, Ph.D. Dissertation, INPE, Brazil, 256 pp., 2003.

Fejer, B. G., Low latitude storm time ionospheric electrodynamics, $J$. Atmos. Sol.-Terr. Phys., 64, 1401-1408, 2002.

Fejer, B. G., J. W. Jensen, T. Kikuchi, M. A. Abdu, and J. L. Chau, Equatorial ionospheric electric fields during the November 2004 magnetic storm, J. Geophys. Res., 112, A10304, doi:10.1029/2007JA012376, 2007.

Forbes, J. M., Dynamics of the thermosphere, J. Meteor. Soc. Jpn., 85, 193-213, 2007.

Fuller-Rowell, T. M., M. V. Codrescu, R. G. Roble, and A. D. Richmond, How does the thermosphere and ionosphere react to a geomagnetic storm?, in Magnetic Storms, Geophys. Monogr. Ser., vol. 98, edited by B. T. Tsurutani et al., pp. 203-225, AGU, Washington, D.C., 1997.

Fuller-Rowell, T. J., G. H. Millward, A. D. Richmond, and M. V. Codrescu, Storm-time changes in the upper atmosphere at low latitudes, J. Atmos. Sol.-Terr. Phys., 64, 1383-1391, 2002.

Gonzales, W. D., J. A. Joselyn, Y. Kamide, H. W. Kroehl, R. Rostoker, G. B. T. Turutani, and V. M. Vasyliunas, What is a geomagnetic storm?, $J$. Geophys. Res., 99(A4), 5771-5792, 1994.

Manju, G., C. V. Devasia Sudha Ravindran, V. Thampi Smitha, and R. Sridharan, Plasmaspheric electron content (PEC) over low latitude regions around the magnetic equator in the Indian sector during different geophysical conditions, J. Atmos. Sol.-Terr. Phys., 1066-1073, 2008.

Mannucci, A. J., B. T. Tsurutani, B. A. Iijima, A. Komjathy, A. Saito, W. D. Gonzalez, F. L. Guarnieri, J. U. Kozyra, and R. Skoug, Dayside global ionospheric response to the major interplanetary events of October 29-30, 2003 "Halloween Storms", Geophys. Res. Lett., 32, 12, doi:10.29/2004GL021467, 2005.

Maruyama, N., A. D. Richmond, S. Sazykins, F. Toffoletto, T. J. FullerRowell, M. Codresscu, D. Anderson, and G. Millward, What determines the properties of prompt penetration Electric fields a case study of April 17, 2002 Storm event, AGU, Spring meeting, 2005.

Mayr, H. G. and H. Volland, Magnetic storm effects in the neutral composition, Planet. Space Sci., 20, 379, 1972.

Mayr, H. G., I. Harris, and N. W. Spencer, Some properties of upper atmosphere dynamics, Rev. Geophys., 16, 539, 1978.

Paxton, L. J. et al., GUVI: A hyper spectral imager for geospace, in Instruments, Science, and Methods for Geospace and Planetary Remote Sensing, edited by C. A. Nardell et al., Proc. SPIE Int. Soc. Opt. Eng., 5660, 227-240, 2004.

Prolss, G. W., Magnetic storm associated perturbations of the upper atmosphere: Recent results obtained by satellite-borne gas analyzers, Rev. Geophys., 18, 183, 1980.

Prolss, G. W., Magnetic storm associated perturbations of the upper atmosphere, in Magnetic Storms, Geophys. Monogr. Ser., vol. 98, edited by B. T. Tsurutani et al., pp. 227-241, AGU, Washington, D.C., 1997.

Richmond, A. D. and G. Lu, Upper-atmospheric effects of magnetic storms: A brief tutorial, J. Atmos. Sol.-Terr. Phys., 62, 1115-1127, 2000.

Simi, K. G., S. V. Thampi, D. Chakrabarty, B. M. Pathan, S. R. Prabhakaran Nayar, and T. Kumar Pant, Extreme changes in the equatorial electrojet under the influence of interplanetary electric field and the associated modification in the low-latitude $\mathrm{F}$ region plasma distribution, J. Geophys. Res., 117, A03331, doi:10.1029/2011JA017328, 2012.

Skoug, R. M., J. T. Gosling, J. T. Steinberg, D. J. McComas, C. W. Smith, N. F. Ness, Q. Hu, and L. F. Burlaga, Extremely high speed solar wind: October 29-30, 2003, J. Geophys. Res., 109, A09102, 9 pp., doi:10.1029/2004JA010494, 2004.

Sobral, J. H. A., M. A. Abdu, W. D. Gonzalez, C. S. Yamashita, A. L. Clua de Gonzalez, I. Batista, and C. J. Zamlutti, Responses of the low latitude ionosphere to very intense geomagnetic storms, J. Atmos. Sol. Terr. Phys., 63, 965, 2001.

Strickland, D. J., R. R. Meier, R. L. Waltersheid, J. D. Craven, A. B. Christensen, L. J. Paxton, D. Morrison, and G. Crowley, Quiet-time seasonal behavior of the thermosphere seen in the far ultraviolet dayglow, J. Geophys. Res., 109, A01302, doi:10.1029/2003JA010220, 2004.

Tsurutani, B., A. Mannucci, B. Iijima, M. A. Abdu, J. H. A. Sobral, W. Gonzalez, F. Guarneri, T. Tsuda et al., Global dayside ionospheric uplift and enhancement associated with interplanetary electric fields, $J$. Geophys. Res., 109, A08302, doi:10.1029/2003JA010342, 2004.

Vlasov, M., M. C. Kelley, and H. Kil, Analysis of ground-based and satellite observations of F-region behavior during the great magnetic storm of July, 2000, J. Atmos. Sol.-Terr. Phys., 65, 1223-1234, 2003.

Zhang, Y., L. J. Paxton, D. Morrison, B. Wolven, H. Kil, C.-I. Meng, S. B. Mende, and T. J. Immel, O/N2 changes during 14 October 2002 storms: IMAGE SI-13 and TIMED/GUVI observations, J. Geophys. Res., 109, A10308, doi:10.1029/2004JA010441, 2004.

Zhao, B., W. Wan, and L. Liu, Responses of equatorial anomaly to the October-November 2003 superstorms, Ann. Geophys., 23, 693, 2005.

K. G. Simi, G. Manju (e-mail: manju_spl@vssc.gov.in), M. K. Madhav Haridas, S. R. Prabhakaran Nayar, Tarun Kumar Pant, and S. Alex 